\title{
Finding Importance for Universal Screening of Familial Hypercholesterolemia
}

\author{
Shinji Yokoyama
}

Chubu University, Aichi, Japan

\section{See article vol. 28: 000-000}

In this issue of Journal of Atherosclerosis and Thrombosis, Matsunaga et al report finding familial hypercholesterolemia $(\mathrm{FH})$ in universal screening by measuring plasma low density lipoprotein cholesterol (LDLC) of school children in Kagawa Prefectural region ${ }^{1)}$. Among the 15665 children subjected, 67 were screened as LDLC $\geq 140 \mathrm{mg} / \mathrm{dL}$ for further genetic analysis and clinical diagnosis of $\mathrm{FH}$. Common causative gene mutations for $\mathrm{FH}$ were identified in 41 and those for sitosterolemia in 1, while Japan Atherosclerosis Society (JAS) guideline for pediatric $\mathrm{FH}^{2)}$ identified only 19 . No homozygote was identified in this particular survey. The prevalence of the confirmed $\mathrm{FH}$ in this cohort is thus as least $1 / 382$, and potentially as high as $1 / 220$ since more than $40 \%$ of clinical $\mathrm{FH}$ may not be identified by common $\mathrm{FH}$ gene mutations ${ }^{3)}$. We find important messages in these results.

First, clinical diagnosis of $\mathrm{FH}$ was found difficult as sensitivity and specificity of the JAS guideline for pediatric FH was only 32 and $77 \%$, respectively ${ }^{1)}$. The guideline must be reviewed and revised to improve its clinical significance by collecting more data from practical application attempt like this study. It seems more sensitive and specific to screen the candidates simply by LDLC directly for genetic analysis. This approach apparently identified most of the FH patients with common mutations having seen their prevalence in the study. Second, the study demonstrated the practical feasibility to introduce nationwide universal screening for $\mathrm{FH}$ children, which would not only save their lives and/or dramatically improve their quality of life in the future, but also would substantially reduce the social cost for public health.
Development of coronary heart disease (CHD) is dependent on age-integrated LDLC so that more reduction of the risk can be expected by the earlier lowering LDLC in FH patients, ${ }^{4,5}$. Onset of CHD has been in fact delayed after introduction of statins into clinical use ${ }^{6}$. . However, contribution of $\mathrm{FH}$ is still high among Japanese CHD patients according to the recent studies, $2.7 \%-5.7 \%$ for all ages and $7.8 \%$ $15.4 \%$ in those under 60 year-old ${ }^{7-9)}$, indicating overall CHD risk of $\mathrm{FH}$ is 10 times higher than general population and would be 30 times under 60 . It is, therefore, important to find $\mathrm{FH}$ patients as early as possible to initiate LDLC-lowering treatment.

CHD is still the top cause of death in Western world, while it remains relatively low in Japan. According to Statistics Japan, annual death by myocardial infarction (MI) and by other CHD both increased during the post-war time until it reached around 50 and 30 thousand cases (total nearly 80 thousand) toward the end of the 20th century, and then both started declining ${ }^{10)}$. The numbers came down to around 33 and 35 thousand (total 68 thousand), respectively, throughout the past 25 years (Fig. 1). The cost of the treatment of CHD in Japanese Healthcare System is around 750 billion yen (BY) but showing slight gradual decrease by a few percent reflecting the decreasing trend of the cases during the ten-year period from 2008 to $2018^{11)}$. This trend is somewhat more apparent as decreasing from 190 to $170 \mathrm{BY}$ for the patients under the age of 65 (Fig. 1). The loss of life by FH-CHD is therefore estimated 2000-2500 a year and the medical cost for all $\mathrm{FH}-\mathrm{CHD}$ is some $25 \mathrm{BY}$ a year. Accordingly, 90\% of them, 1800-2250 FH lives and 22.5 BY a year, can be saved when their risk is reduced to the same level as general population by treating LDLC from their childhood $^{4)}$. Instead, the cost for LDLC-lowering treatment can be around 6 BY a year assuming that all 


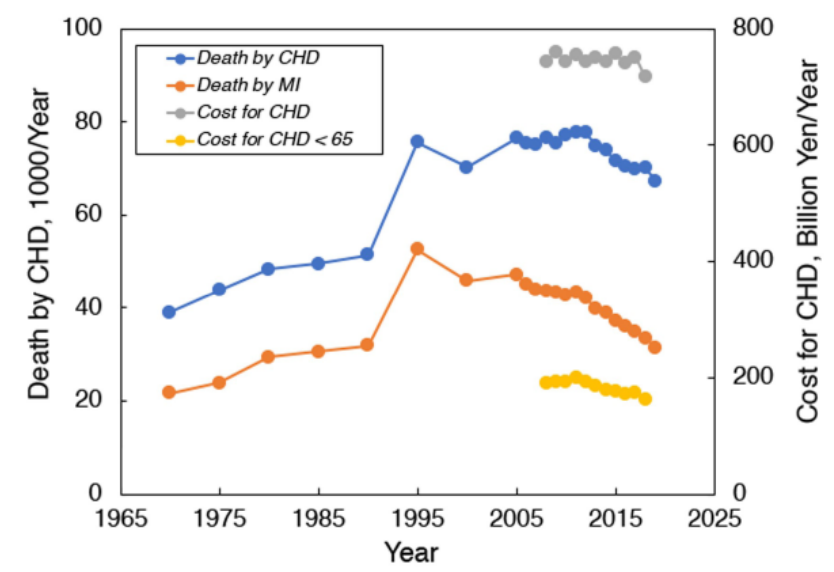

Fig. 1. Chronological profile of death by coronary heart disease (CHD) and myocardial infarction (MI) (on left axis) and the cost of medical care for CHD in all ages and under 65 (on right axis). The data are taken from Statistics Japan ${ }^{10,11)}$.

500 thousand $\mathrm{FH}$ heterozygotes are prescribed generic super-strong statins at the level 3 (rosuvastatin $10 \mathrm{mg}$ or atorvastatin $20 \mathrm{mg}$ a day), estimated 30 yen a day.

Universal screening of $\mathrm{FH}$ is thus an important, urgent, practical, and feasible issue for Japanese public health with respect to significant reduction of CHD, for saving lives, improving quality of life, reducing the direct medical cost and easing burden on medical resources, and eventually resulting in saving a large amount of social cost. Ministry of Health, Welfare and Labour of Japan currently enforces universal screening tests for 23 inborn metabolic diseases such as phenylketourea, in which development of mental retardation can be prevented by introducing specific appropriate diet and life-styles ${ }^{12)}$. $\mathrm{FH}$ is a more common and easy-to-find metabolic disorder and its serious future outcome is well preventable. More substantial amount of social cost can be saved by enforcement of universal mass screening system for $\mathrm{FH}$.

\section{Acknowledgement}

The author is grateful to Health, Labor and Welfare Sciences Research Grant for Research on Rare and Intractable Diseases and to a Grant-in-Aid from MEXT (21K11586).

\section{Conflicts of Interest}

The author has no conflict of interest to declare related to this article.

\section{References}

1) Matsunaga K, Mizobuchi A, Fu HY, Ishikawa S, Tada H, Kawashiri M, Yokota I, Sasaki T, Ito S, Kunikata J, Iwase T, Hirao T, Yokoyama K, Hoshikawa Y, Fujisawa T, Dobashi K, Kusaka T, Minamino T: Universal screening for familial hypercholesterolemia in children in Kagawa, Japan. J Atheroscler Thromb, 2021; In Press: doi: http:// doi.org/10.5551/jat.62780

2) Harada-Shiba M, Ohta T, Ohtake A, Ogura M, Dobashi K, Nohara A, Yamashita S, Yokote K: Guidance for pediatric familial hypercholesterolemia 2017. J Atheroscler Thromb, 2018; 25: 539-553

3) Hori M, Ohta N, Takahashi A, Masuda $H$, Isoda R, Yamamoto S, Son C, Ogura M, Hosoda K, Miyamoto Y, Harada-Shiba M: Impact of LDLR and PCSK9 pathogenic variants in Japanese heterozygous familial hypercholesterolemia patients. Atherosclerosis, 2019; 289: 101-108

4) Mabuchi H, Koizumi J, Shimizu M, Takeda R: Development of coronary heart disease in familial hypercholesterolemia. Circulation, 1989; 79: 225-232

5) Nordestgaard BG, Chapman MJ, Humphries SE, Ginsberg HN, Masana L, Descamps OS, Wiklund O, Hegele RA, Raal FJ, Defesche JC, Wiegman A, Santos RD, Watts GF, Parhofer KG, Hovingh GK, Kovanen PT, Boileau C, Averna M, Borén J, Bruckert E, Catapano AL, Kuivenhoven JA, Pajukanta P, Ray K, Stalenhoef AF, Stroes E, Taskinen MR, Tybjærg-Hansen A: Familial hypercholesterolaemia is underdiagnosed and undertreated in the general population: Guidance for clinicians to prevent coronary heart disease: Consensus statement of the European Atherosclerosis Society. Eur Heart J, 2013; 34: 3478-3490a

6) Harada-Shiba $M$, Sugisawa $T$, Makino $H$, Abe $M$, Tsushima M, Yoshimasa Y, Yamashita T, Miyamoto Y, Yamamoto A, Tomoike H, Yokoyama S: Impact of statin treatment on the clinical fate of heterozygous familial hypercholesterolemia. J Atheroscler Thromb, 2010; 17: 667-674

7) Ohmura H, Fukushima Y, Mizuno A, Niwa K, Kobayashi Y, Ebina T, Kimura K, Ishibashi S, Daida H: Estimated prevalence of heterozygous familial hypercholesterolemia in patients with acute coronary syndrome. Int Heart J, 2017; 58: 88-94

8) Harada-Shiba M, Ako J, Arai H, Hirayama A, Murakami Y, Nohara A, Ozaki A, Uno K, Nakamura M: Prevalence of familial hypercholesterolemia in patients with acute coronary syndrome in japan: Results of the EXLORE-J study. Atherosclerosis, 2018; 277: 362-368

9) Tanaka N, Teramoto T, Yokoyama S: Application of the japanese guidelines for the diagnosis of familial hypercholesterolemia in general practice: It is to be validated in international harmonization. J Atheroscler Thromb, 2019; 26: 93-98

10) https://www.e-stat.go.jp/dbview?sid=0003411672 (in Japanese)

11) https://www.e-stat.go.jp/stat-search/files?page=1 \&toukei= $00450032 \&$ tstat $=000001020931$ (in Japanese)

12) https://www.jsms.gr.jp/download/MHLW_MCH_20180 330.pdf (in Japanese) 